\title{
Assisted Methods for Optimization in Robotics
}

\author{
Adrian D. Olaru, Mikulas E. Hajduk, Serban A. Olaru, Niculae C. Mihai, and Natalia M. Smidova
}

\begin{abstract}
Optimization of the elements and systems from Robotics is one of the most complicated problem with the final goal to obtain the end-effecters' 3D extreme space precision trajectory. In the paper are shown some of the proper methods for optimization in Robotics: optimal Extenics choose of the precision- stability working point of one linear hydraulic cylinder; modelling and optimization of the DC electrical drive of the robots; optimising the dynamic behaviour of the robots by using the intelligent dampers; optimise the inverse kinematics results by using one complex proper method; optimise the multi robots application by using the algorithm to choose the optimal application points of the robots' bases and by construct the parallel robot structure using three arm type robots. All applied method solves one small part of the complex problems of the optimisation in robotics.
\end{abstract}

Index Terms-Assisted optimization LabVIEW methods, forward kinematics, inverse kinematics, dynamic behavior, 3D space trajectory.

\section{INTRODUCTION}

Precision and stability of all dynamic systems is one of the more important contradictory problem what must be solved. This problem is contradictory because if we try to increase the precision imposed from the application, decrease the stability and will be possible to touch the limit of stability, when the element or system can't be controlling more, otherwise if we try to increase the stability, the precision will decrease and the element or system is very slow and will don't respect the minimal promptitude desired limit. The Extenics theory was created by prof. Cai Wen in 1983 by publishing the paper "Extension Set and Non-Compatible Problems"[1]-[3]. Its goal was to solve contradictory problem and also nonconventional ideas in many fields of technical, social, philosophical and architectural. Usually the Extenics theory operate with some extension transformation what change the problem from the contradictory field in to non-contradictory by extend the universe of discourse and respect the same value of the dependent function. Some used mining of the transformation [1]-[3] are substitution, increasing/decreasing, expansion/contraction, and some complex transformation like expansion-duplication, approximation-duplication, substitution- increasing. Many of the contradictory problem can't be solved by using only

Manuscript received September 9, 2017; revised October 30, 2017. This work was supported in part by the RUSOS European project and was realized together with the mechatronics companies RomSYS S.A from Romania and TechnoAccord from Quebec, Canada.

A. D. Olaru is with the University Politehnica of Bucharest, Romania (e-mail: aolaru_51@ymail.com).

M. Hajduk and N. Smidova are with Technical University of Kosice, Slovakia.

S. A. Olaru was with RomSys SA, Bucharest, Romania (e-mail: serban1978@yahoo.com).

N. C. Mihai is with the TechnoAccord SA, Quebec, Canada (e-mail: mniculae@gmail.ca). one transformation and must be applied many successive or simultaneously transformations.

The other more important thing in the optimization field of the robots' is the dynamic behavior. The paper presents one assisted method with the proper virtual LabVIEW instruments $(V I)$ for the assisted of the theoretical and experimental research of the industrial robots with DC motors. The virtual instruments were achieved in the LabVIEW $^{\mathrm{TM}}$ soft 8.2 from National Instruments, USA. The $V I$-s simulates the open and closed loop of the DC servo systems, and the data acquisition of the velocity and acceleration and generate the Fourier spectrum with the final goal to compare simulation results with the real results [4]-[9]. This method will be possible to be used in the assisted research of the many other mechanical applications where it is necessary to know the dynamic behavior, the vibration spectrum and how the constructive and functional parameters of the DC servo systems and the movements cases (the equilibrium of the robot's arm) determine the major changes of the spectrum and of the dynamic behavior. Now, in the world, all the dynamic determination of the dynamic behavior, of the vibration spectrum are made with some complex apparatus with the expensive cost.

This paper tries to develop one general assisted methodology of the dynamic behavior in the real and frequency domain of the articulated arm type robot. In the paper were solved the following problems: the theoretical and the experimental assisted research with data acquisition by using the proper theoretical and experimental LabVIEW $V I$; the optimization of the dynamic behavior with the virtual proper VI-s; the choice of the optimal DC motor and the parameters for closed loop, to obtain one better dynamic behavior results. In the world, the actual research does not approach the assisted virtual instrumentation for the optimization of the dynamic behavior [10]-[15].

The Global Dynamic Compliance (GDC) [16]-[20] is one of the most important parameter in the dynamic behavior of the industrial robot. In the manufacturing systems is necessary to know the vibration behavior of the robot, the Viscose Global Dynamic Damper Coefficient (VGDDC), or the Viscose Global Dynamic Damper Equivalent Coefficient $(V G D D E C)$ of his structure and how the dynamic variation of acceleration determines the damped mechanical vibrations, to avoid the resonance frequencies from the Fourier spectrum. The paper shows for the first time one assisted research method with proper virtual LabVIEW ${ }^{\mathrm{TM}}$ instruments for determining the $G D C, V G D D C, V G D D E C$ of the industrial robots. The virtual instruments were achieved in the LabVIEW soft 8.2 full development from National Instruments, USA. These virtual apparatus are generally, we can use them in many others mechanical researches and applications. Now, in the world, the GDC are not determined for the robots and for that this paper presents a novelty in this field.

The complex task of controlling the movements of all joints of a robot in mono and multi robot applications 
requires some Virtual Instrumentations $(V I)$ in order to achieve the following goals: (i) generating points on the required spatial curves; (ii) simulating the robot's joints according to their internal coordinates and forward kinematics; (iii) generating internal coordinates for one known point from the space required curve; (iv) generating internal coordinates for all known external coordinates (points) of the imposed space curve; (v) generating the file with internal coordinates transposed into relative and absolute number of pulses for each motor.

\section{EXTENICS THEORY APPLIED TO ROBOTICS}

\section{A. Generality about Extenics Theory}

In all study cases the modeling and simulation offer some on-line results what can be used to choose some optimal constructive and functional parameters to obtain one required dynamic behavior: without vibration, one short acceleration time, minimal stationary errors, one bigger Bode frequency, one higher cutting Bode frequency, one higher proper and natural frequencies. In the proper research paper [9] was shown that the working point obtained by Extenics theory is formed by $x$ coordinate of the precision limit point and $y$ coordinate of the stability limit point, because the $y$ coordinate determine the increasing of the proper frequency with effect to the increasing the precision and decreasing the stability and $x$ determine the increasing of the damper factor with effect to the increasing of stability and decreasing the precision. In this case (partial solving case) the solution of the contradictory problem can be written in the following form $S=\left(\begin{array}{c}x \text { (precision_limitpo int }) \\ y(\text { stability_limitpo int })\end{array}\right)$

and the compatible degree functions $k(x), k(y)$ and compatible degree of the contradictory problem $K\left(P_{x}\right)$ and $K\left(P_{y}\right)$.

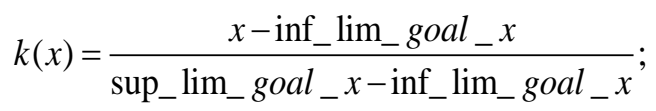

$$
\begin{aligned}
& k(y)=\frac{y-\text { inf_lim_goal_}_{-} y}{\text { sup_lim_goal_y }_{-} \text {inf_lim_goal_ } y} ;
\end{aligned}
$$

\section{Extenics precision} limit'point

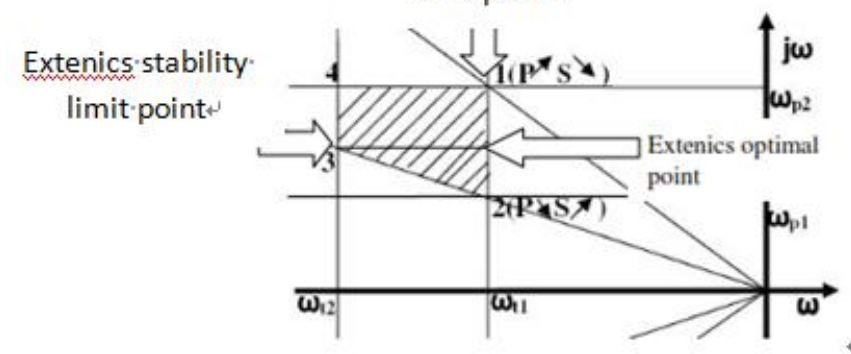

Fig. 1. The poles-zerous plane with partial result after applying the basic Extenics logical method.

\section{B. Application in the Linear Hydraulic Cylinder}

Contradictory problem is one of the more important think to solve in the technical field, because not be possible to use one hydraulic cylinder in the robotics field that must be precise and stable without Extenics solving the contradictory problem.
LabVIEW simulation contents the simulation of the root's locus and dependent formula, Fig. 2. After applying the mathematical model of the Extenics dependent function for 2D dimension and increasing/ decreasing transformations were obtained some results, figs.3. The Extenics theory was accomplished with the proper remarks and concepts [9]. We remark that the partial solution is not singular inside of the minimal attraction field. For that was applied the dependent formula for more other working points $\mathrm{P}_{1}-\mathrm{P}_{5}$ what there are very close to this determined Exetenics area, to establish if all these points are in the same precision-stability class or represent the new one precision -stability class. Analyzing the obtained simulation data for the dependent formula, fig. 4 we can remarks the following: all points is in the acceptabledesirable 2D field, exception, $\mathrm{P}_{4} ; \mathrm{P}_{1}$ is the optimal working point determined by Extenics theory. $\mathrm{P}_{1,2,3,5}$ there are in the same precision-stability class by the established desirableacceptable $2 \mathrm{D}$ fields. $\mathrm{P}_{4}$ is not acceptable point in the precision-stability class. The research can be more precise and for that can be used one new contraction transformation to reduce the acceptable field and will remain inside of the acceptable field only $\mathrm{P}_{1,2,3}$. These remarks are very important for the researchers to establish very easily and correctly the precision-stability class of the hydraulic cylinder, like was remarked in this study case.

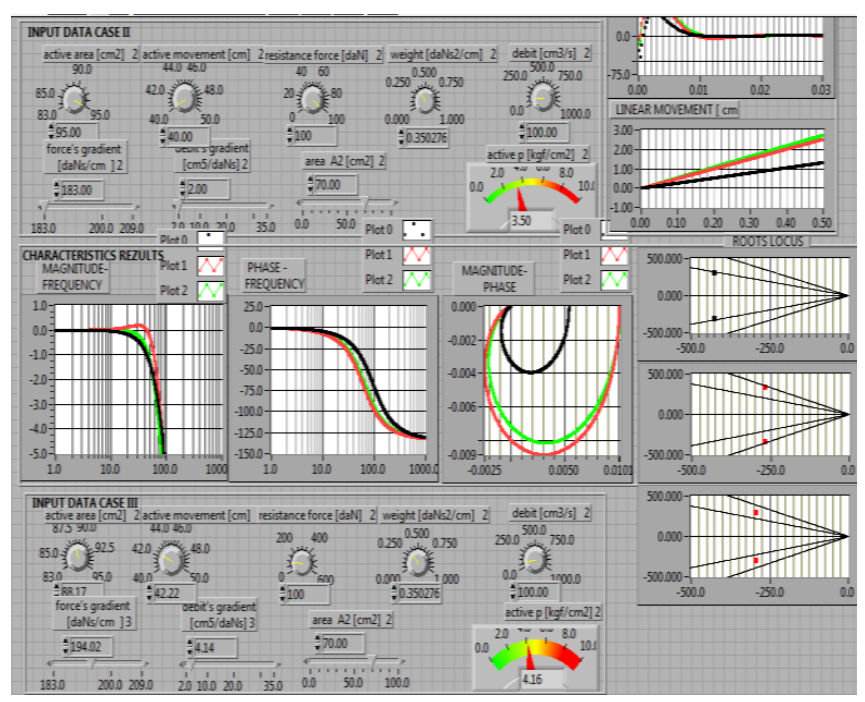

Fig. 2. Front panel of the LabVIEW VI that simulate the hydraulic cylinder dynamic behavior.
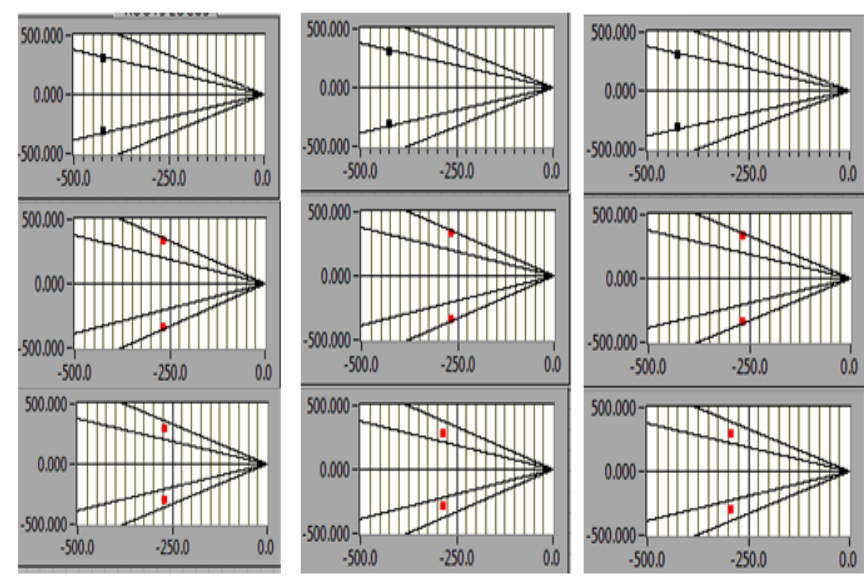

Fig. 3. Comparative root's locus for the intermediate and for partial optimal solution after applying the Extenics theory. 


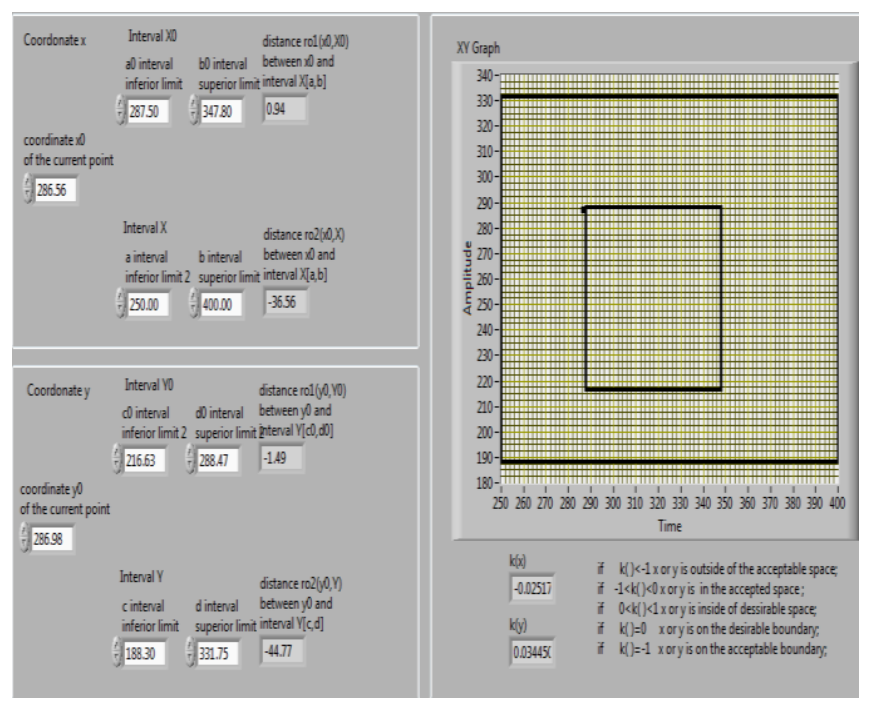

Fig. 4. Some results after applying the Extenics dependent formula.

$P_{1}=\left\{\begin{array}{l}286,556 \\ 286,979\end{array}\right\}\left\{\begin{array}{l}k_{1}(x)=-0.025 ; k<0 \Rightarrow x \in X \\ k_{1}(y)=0.03 ; 0<k<1 \Rightarrow y \in Y_{0}\end{array}\right\} \Rightarrow$ acceptable_desirable_point

$P_{2}=\left\{\begin{array}{l}292,964 \\ 286,979\end{array}\right\}\left\{\begin{array}{l}k_{2}(x)=0.145 ; 0<k<1 \Rightarrow x \in X_{0} \\ k_{2}(y)=-0.100 ;-1<k<0 \Rightarrow y \in Y\end{array}\right\} \Rightarrow$ desirable_acceptable_point

$P_{3}=\left\{\begin{array}{l}298,324 \\ 297,505\end{array}\right\}\left\{\begin{array}{l}k_{3}(x)=0.288 ; 0<k<1 \Rightarrow x \in X_{0} \\ k_{3}(y)=-0.208 ;-1<k<0 \Rightarrow y \in Y\end{array}\right\} \Rightarrow$ desirable_acceptable_point

$P_{4}=\left\{\begin{array}{l}358.773 \\ 340.217\end{array}\right\}\left\{\begin{array}{l}k_{4}(x)=-0.21 ;-1<k<0 \Rightarrow x \in X \\ k_{4}(y)=-1.195 ; k<-1 \Rightarrow y \notin Y_{0}, Y\end{array}\right\} \Rightarrow$ acceptable_nonacceptable_point

$P_{5}=\left\{\begin{array}{l}338,623 \\ 327,842\end{array}\right\}\left\{\begin{array}{l}k_{5}(x)=0.175 ; 0<k<1 \Rightarrow x \in X_{0} \\ k_{5}(y)=-0.909 ;-1<k<0 \Rightarrow y \in Y\end{array}\right\} \Rightarrow$ desirable_acceptable_point

\section{Extenics Transformation and Precision-Stability Case}

Contraction transformation was applied with the reason that working point $(x, y)$ to be closer to the constraint precision-stability area imposed by the researcher.

Extension/Contraction transformation was applied with $\alpha$ factor for each of axes. About this factor will adapted the $\alpha$, factor that will be applied for all cases studied parameters of the hydraulic cylinder. This factor will be calculated versus limits values for each of the parameters and will be different for all parameters.

$$
\begin{aligned}
& T X_{0}=\alpha X_{0} ; T X=\alpha X \\
& T Y_{0}=\alpha_{0} Y_{0} ; T Y=\alpha Y \\
& \alpha_{i}^{\prime}=\frac{\inf (\lim \text { param.value })_{i}}{\sup (\lim . \text { param.value })_{i}} \\
& \alpha_{i}^{\prime \prime}=\frac{\alpha_{i}^{\prime}}{\text { nr.steps }}
\end{aligned}
$$

where $\alpha>1$ for the extension and $0<\alpha<1$ for the contraction what will be applied to the interval $\mathrm{X}$ and $\mathrm{Y}, \alpha$ is the total adapted increasing/decreasing factor and $\alpha$ "is the adapted increasing/decreasing factor for the first step value. Some of the data must be increasing and other decreasing, finally defined the minimal working attraction field [9]. The other way of the research was to define different values of the factor. When the $\alpha "<<1$ will be calculated other value with the condition to respect the step value, all values for increasing or decreasing will be multiplier or de-multiplier with this new value, other will be calculate with $1-\alpha$ " or $1+\alpha$ ". The Extenics transformation will be applied to determine the desirable field for each of the Stability and Precision parameter's values. Each of the current determined field will be the new desirable field and the last one will be the acceptable field in each iteration process. The novelty of the Extenics applied method was to use in the research the different factor for increasing and decreasing values for each of the studied constructive and functional parameters limits and alternating them or each iteration to assure the convergence process and finally to obtain the minimal working attraction field. The value of the transformation factor $\alpha$ " was de multiplied by 2 for each steps, to assure the asimptoticaly neighbour to the minimal attraction field.

TABLE I: DATA CALCUlATED AFTER APPLIED EXTENICS TRANSFORMATION FOR THE VALUE OF A'<1

\begin{tabular}{|c|c|c|c|c|c|c|c|}
\hline \multicolumn{2}{|c|}{$\alpha=0.1$} & \multicolumn{2}{c|}{$\alpha=0.05$} & \multicolumn{2}{c|}{$\alpha=0.025$} & \multicolumn{2}{c|}{$\alpha=0.012$} \\
\hline $\mathrm{S}$ & $\mathrm{P}$ & $\mathrm{S}$ & $\mathrm{P}$ & $\mathrm{S}$ & $\mathrm{P}$ & $\mathrm{S}$ & $\mathrm{P}$ \\
\hline 91.3 & 85.5 & 86.7 & 89.77 & 88.9 & 87.52 & 87.83 & 88.57 \\
\hline 31.5 & 2.2 & 29.9 & 2.31 & 29.17 & 2.36 & 28.81 & 2.38 \\
\hline 188.1 & 201.3 & 197.5 & 191.2 & 192.5 & 196 & 194.8 & 193.6 \\
\hline 45 & 44 & 42.75 & 41.8 & 41.68 & 42.84 & 42.18 & 42.32 \\
\hline
\end{tabular}

\begin{tabular}{|c|c|c|c|c|c|}
\hline \multicolumn{2}{|c|}{$\alpha=0.006$} & \multicolumn{2}{c|}{$\alpha=0.003$} & \multicolumn{2}{c|}{$\alpha=0.001$} \\
\hline $\mathrm{S}$ & $\mathrm{P}$ & $\mathrm{S}$ & $\mathrm{P}$ & $\mathrm{S}$ & $\mathrm{P}$ \\
\hline 88.35 & 88.03 & 88.08 & 88.29 & 88.16 & 88.2 \\
\hline 28.63 & 2.39 & 28.54 & 2.39 & 28.51 & 2.39 \\
\hline 193.7 & 194.8 & 194.2 & 194.2 & 194 & 194 \\
\hline 42.43 & 42.06 & 42.3 & 42.18 & 42.25 & 42.22 \\
\hline
\end{tabular}

The studied points $\mathrm{P}_{1-5}$ have the following simulation parameters:

$$
P_{1}=\left\{\begin{array}{l}
88.16 \\
2.39 \\
194 \\
42.22
\end{array}\right\} ; P_{2}=\left\{\begin{array}{l}
88.16 \\
3.98 \\
194 \\
42.22
\end{array}\right\} ; P_{3}=\left\{\begin{array}{l}
88.16 \\
5.31 \\
194 \\
42.22
\end{array}\right\} ; P_{4}=\left\{\begin{array}{l}
88.16 \\
20 \\
194 \\
42.22
\end{array}\right\} ; P_{5}=\left\{\begin{array}{l}
88.16 \\
15 \\
194 \\
42.22
\end{array}\right\}
$$

where the data values are: aria $\mathrm{A}=88.16\left[\mathrm{~cm}^{2}\right]$; flow gradient $\mathrm{a}_{\mathrm{m}}=2.39 ; 3.98 ; 5.31 ; 20 ; 15\left[\mathrm{~cm}^{5} / \mathrm{daNs}\right] ;$ force versus velocity gradient $b_{m}=194[$ daNs $/ \mathrm{cm}$; active movement $\mathrm{c}=42.22[\mathrm{~cm}]$. After applying the Extenics theory and the assisted determination of the dependent $2 \mathrm{D}$ formula for each of these points, we were obtained the results from (2). The applied values were determined by apply the logical Extenics theory with $A N D$ function between the goals and conditions matter-elements [9].

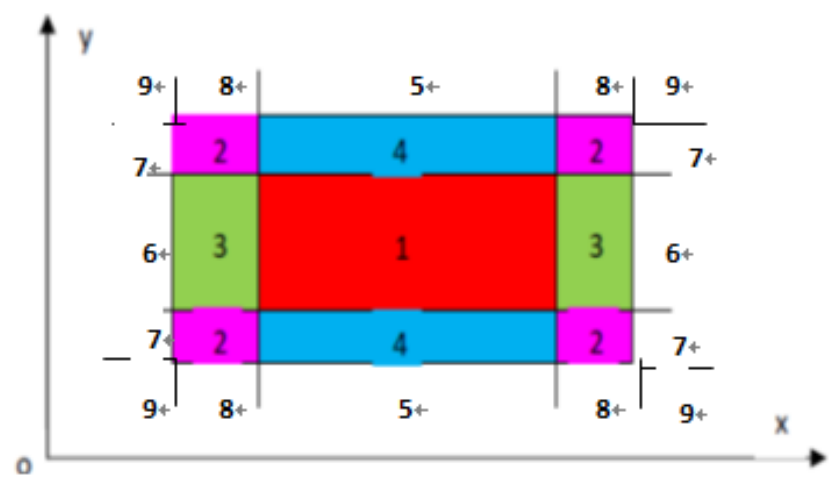

Fig. 5. Class of precision- stability by extenics.

$\left\{\begin{array}{l}x \Rightarrow \text { desirable } \\ y \Rightarrow \text { desirable }\end{array}\right\} ;$
2-Full desirable acceptable $\left\{\begin{array}{l}x \Rightarrow \text { acceptable } \\ y \Rightarrow \text { acceptable }\end{array}\right\} ;$ 


$$
\begin{aligned}
& \text { 3-Partial acceptable }\left\{\begin{array}{c}
x \Rightarrow \text { acceptable } \\
y \Rightarrow \text { desirable }
\end{array}\right\} \text {; } \\
& \text { 4-Partial desirable }\left\{\begin{array}{c}
x \Rightarrow \text { desirable } \\
y \Rightarrow \text { acceptable }
\end{array}\right\} \text {; } \\
& \text { 5-Partial acceptable }\left\{\begin{array}{c}
x \Rightarrow \text { desirable } \\
y \Rightarrow \text { nonacceptable }
\end{array}\right\} \text {; } \\
& \left(M^{0}\right)=\left[k_{m_{i}}\right]\left(i_{a_{i}}\right) \\
& \left(U_{i}\right)-\left(e_{i}\right)=\left[R_{a_{i}}\right]\left(i_{a_{i}}\right)+\left[L_{a_{i}}\right]\left(\frac{d i_{a_{i}}}{d t}\right) \\
& \text { 6-Partial acceptable }\left\{\begin{array}{c}
x \Rightarrow \text { nonacceptable } \\
y \Rightarrow \text { desirable }
\end{array}\right\} \\
& \text { 7- Partial acceptable }\left\{\begin{array}{c}
x \Rightarrow \text { nonacceptable } \\
y \Rightarrow \text { acceptable }
\end{array}\right\} \text {; } \\
& \text { 8- Partial acceptable }\left\{\begin{array}{c}
x \Rightarrow \text { acceptable } \\
y \Rightarrow \text { nonacceptable }
\end{array}\right\} \text {; } \\
& \text { 9- Full nonacceptable } \mid x \Rightarrow \text { nonacceptable } \mid \\
& \left\{\begin{array}{l}
x \Rightarrow \text { nonacceptable }
\end{array}\right\}
\end{aligned}
$$

By applying the extended transformation and dependent formula for $2 \mathrm{D}$ were obtained the optimal results what solve the contradictory problem. The applied method LabVIEW instrumentation assures the precise results and validate some of Extenics relations. The obtained results, the applied method, all LabVIEW instrumentation and all remarks about 2D classes assures for the research the way for solving better the contradictory problems. For the future will be applied the complex extension transformation method and extension strategy generating optimal smart system.

\section{Modeling AND OptimizATION OF DC DRIVE}

Assisted modeling and optimization of DC drive open the way to create the smart systems. All activities used the special created LabVIEW $V I$-s to simulate the open and closed loop of the DC servo systems, and the data acquisition of the Fourier spectrum of the acceleration, the acquisition of the velocity with the final goal to compare the simulate with the real results to validate the model and adjust the mathematical model [19], [20]. This method will be possible to be used in the assisted research of the many other mechanical applications where it is necessary to know the dynamic behavior, the vibration spectrum and how the constructive and functional parameters of the DC servo systems and the movements cases (the equilibrium of the robot's arm) determine the major changes of the spectrum and of the dynamic behavior. Now, in the world, all the research of the dynamic behavior, of the vibration spectrum are made with some complex apparatus with the expensive cost without possibility to choose the optimal solution.

This work contains the research of the theoretical and experimental dynamic behavior of the arm type robot in the different cases of the movements with or without springs in the second joint, by using the virtual LabVIEW instrumentation [20].

This paper tries to develop one general assisted methodology of the dynamic behavior in the real and frequency domain of robots. In the paper were solved the following problems: the theoretical and the experimental assisted research with data acquisition by using the proper theoretical and experimental LabVIEW VI; the optimization of the dynamic behavior with the virtual proper VI-s; the choice of the optimal DC and closed loop parameters to obtain one better dynamic results. The actual research in the world does not approach the assisted virtual instrumentation for the optimization of the dynamic behavior [ ].

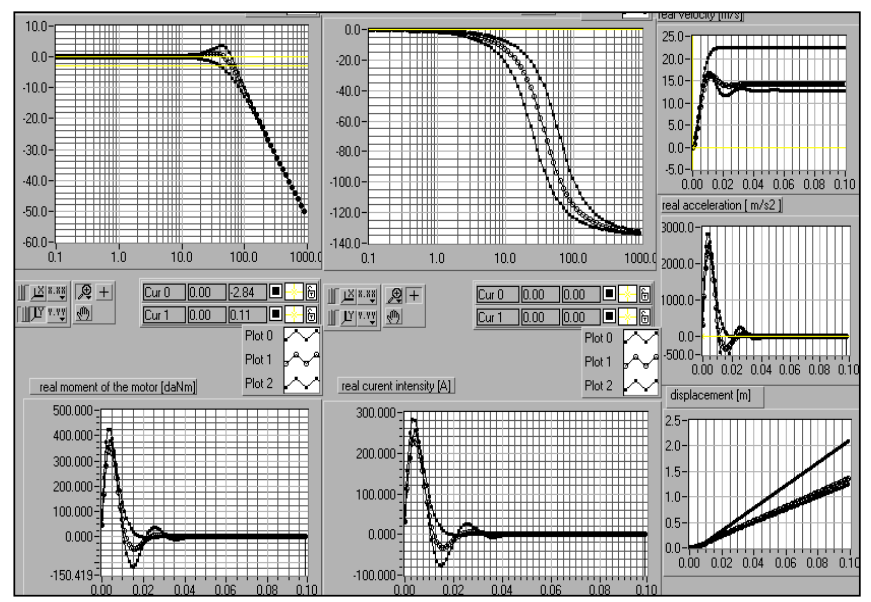

Fig. 6. The front panel of the VI with the real and frequency comparative characteristics when was changed rotor resistance $R_{\mathrm{a}}: 0.33,0.5$ and $0.8(\Omega)$.

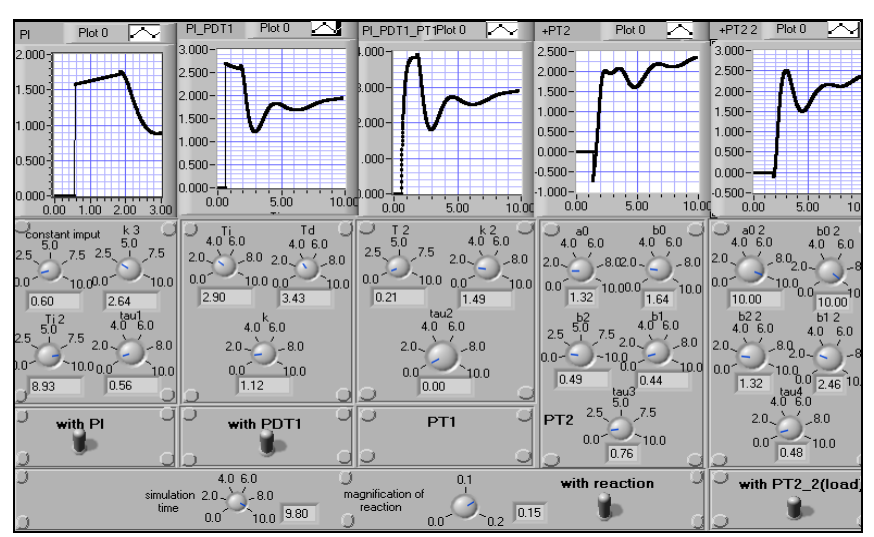

Fig. 7. Front panel of the virtual instrument for the assisted theoretical analyze of the DC servo system.

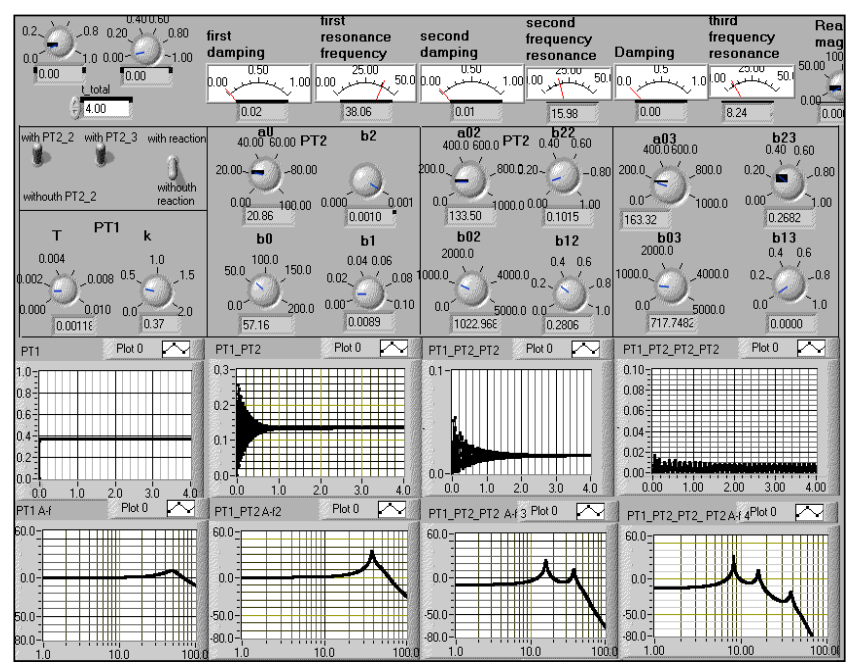

Fig. 8. Front panel of the virtual instrument for the assisted theoretical research of the dynamic behavior of the DC servo system without reaction.

$$
\left(\begin{array}{c}
F^{0} \\
M^{0}
\end{array}\right)=\left[\begin{array}{cc}
z_{u} & 0 \\
0 & z_{u}
\end{array}\right]\left(\begin{array}{c}
D_{0, i} F_{R}^{i} \\
D_{0, i} M_{R}^{i}
\end{array}\right)-\operatorname{diag}\left[\operatorname{sign} \frac{v_{u}^{i}}{\left|v_{u}^{i}\right|} m_{u_{i}} \quad \operatorname{sign} \frac{\omega_{u}^{i}}{\left|\omega_{u}^{i}\right|} J_{g_{i}}\right] \cdot\left(\begin{array}{c}
\left(a_{i, 0}^{i}\right)+\left[\widehat{\omega}_{i, 0}^{i}\right]^{2}\left(r_{g_{i}}^{i}\right) \\
\left(\varepsilon_{i, i-1}^{i}\right)+\left[\omega_{i-1,0}^{i}\right]\left(\omega_{i, i-1}^{i}\right)
\end{array}\right)+
$$$$
+\left[\begin{array}{cc}
z_{u} & 0 \\
0 & z_{u}
\end{array}\right] \cdot\left(\left[G_{i, k}\right]\left(\widehat{b}_{i, k}\right)\left(\left(D_{0, i} F_{R}^{i}\right)-\operatorname{diag}\left[\operatorname{sign} \frac{v_{u}^{i}}{\left|v_{u}^{i}\right|} m_{u_{i}}\right] \cdot\left[D_{0, i}\right]\left(\left(a_{i, 0}^{i}\right)+\left[\widehat{\omega}_{i, 0}^{i}\right]^{2}\left(r_{g_{i}}^{i}\right)\right)\right)\right) \text {, }
$$ 


$$
\begin{aligned}
& \left(M^{0}\right)=\left[k_{m_{i}}\right]\left(i_{a_{i}}\right) \\
& \left(U_{i}\right)-\left(e_{i}\right)=\left[R_{a_{i}}\right]\left(i_{a_{i}}\right)+\left[L_{a_{i}}\right]\left(\frac{d i_{a_{i}}}{d t}\right)
\end{aligned}
$$

where: $\boldsymbol{F}^{\mathbf{0}}$ is the active forces matrix in a Cartesian fixed system; $\boldsymbol{M}^{\mathbf{0}}$ - the active moment matrix in a Cartesian fixed system; $z_{u^{-}}$joint bodies matrix; $\boldsymbol{D}_{\boldsymbol{i - 1}}{ }^{i}$ - transfer matrix between $i-1$ and $i$ body; $\boldsymbol{F}_{\boldsymbol{R}^{-}}$resistant forces matrix; $\boldsymbol{M}_{\boldsymbol{R}}-$ resistant moments matrix; $\boldsymbol{m}_{\boldsymbol{i}^{-}}$mass matrix of bodies; $\boldsymbol{J}_{\boldsymbol{g} i}{ }^{0}$ inertial tensor matrix of bodies; $\boldsymbol{a}_{\boldsymbol{i}, \boldsymbol{o}^{-}}{ }^{\boldsymbol{}}$ absolute dual acceleration matrix in a $i$ body Cartesian system; $\boldsymbol{\omega}_{i, \boldsymbol{o}^{\boldsymbol{i}}}^{\boldsymbol{i}}$ - non symmetric absolute angular velocity matrix in a $i$ body Cartesian system; $\boldsymbol{\varepsilon}_{i, i-1}{ }^{i}$ - angular relative acceleration matrix in a $i$ body Cartesian system; $\boldsymbol{\omega}_{i, i-1}{ }^{i}$ - angular relative velocity in a $i$ body Cartesian system; $\boldsymbol{B}^{\wedge}$ - modified arm type matrix; $\boldsymbol{k}_{\boldsymbol{m} i}$ - matrix of gradient moment- intensity of the DC motors; $\boldsymbol{i}_{a i^{-}}$matrix of the current intensity of all DC motors; $\boldsymbol{U}_{\boldsymbol{i}}-$ matrix of electrical tensions; $\boldsymbol{e}_{\boldsymbol{i}}-$ matrix of DC intern tensions; $\boldsymbol{R}_{a i}$ - matrix of rotor DC resistance; $\boldsymbol{L}_{a i}-$ matrix of the DC inductances.

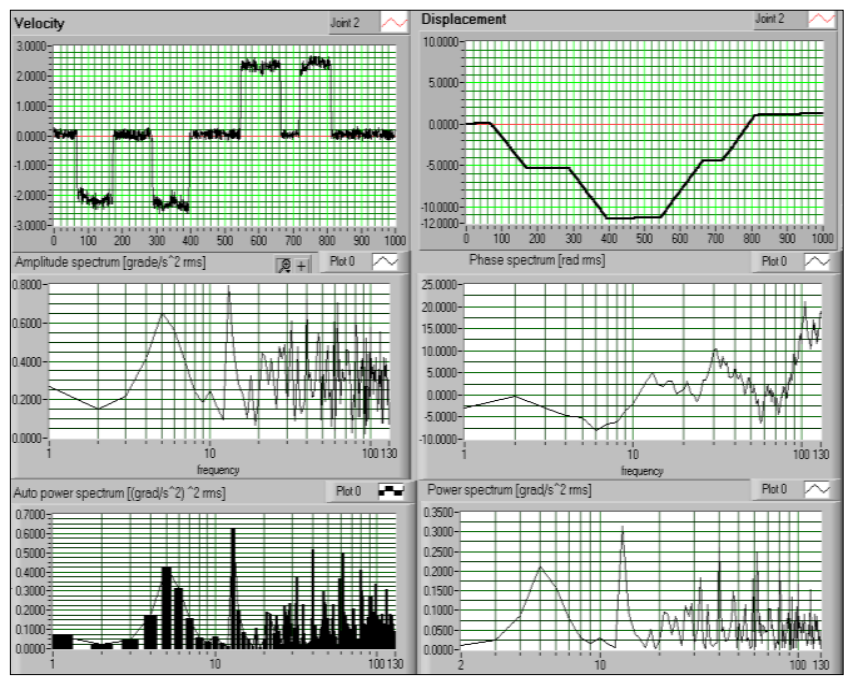

Fig. 9. Velocity, space and Fourier spectrum characteristics in two senses of the movements with delay and magneto rheological damper and spring.

After analysing the theoretical and experimental results of the DC servosystems we can do the following remars: the virtual proper LabVIEW ${ }^{\mathrm{TM}}$ instrumentation created with the goal to assure the theoretical and experimental research aids to obtain and compare some teoretical and experimental results and assure one short time for the research and good results; LabVIEW VI for the theoretical research of the DC motor on created using the proper mathematical matrix model; the theoretical results obtained by changing some functional or constructive parameters of the DC motor or system aids the designers to choose the optimal values for these parameters; with the experimental research was possible to compare the theoretical and experimental results and to modify and ajust the mathematical model to validate them; by using the MRD was created the possibility to design in the future one intelligent assisted sistem. All LabVIEW creted VI-s and the research methode are generaly; they can be used in many other mechanical applications.

\section{OPTIMIZATION OF THE DYNAMIC BEHAVIOR}

The mathematical model of the robots was created according to the mechanical simplified schema of the studied robot, Fig. 10 and have the following form:

$$
\begin{aligned}
& {\left[\begin{array}{ccc}
\tilde{m}_{2} & 0 & 0 \\
0 & \tilde{m}_{3} & 0 \\
0 & 0 & \tilde{m}_{4}
\end{array}\right] \cdot\left(\begin{array}{c}
\tilde{\ddot{x}}_{2} \\
\tilde{\ddot{x}}_{3} \\
\tilde{\ddot{x}}_{4}
\end{array}\right)+\left[\begin{array}{ccc}
\tilde{c}_{2}+\tilde{c}_{3} & -\tilde{c}_{3} & 0 \\
-\tilde{c}_{3} & \tilde{c}_{3}+\tilde{c}_{4} & -\tilde{c}_{4} \\
0 & -\tilde{c}_{4} & \tilde{c}_{4}
\end{array}\right] \cdot\left(\begin{array}{c}
\tilde{\dot{x}}_{2} \\
\tilde{\dot{x}}_{3} \\
\tilde{\dot{x}}_{4}
\end{array}\right)+} \\
& {\left[\begin{array}{ccc}
\tilde{k}_{2}+\tilde{k}_{3} & -\tilde{k}_{3} & 0 \\
-k_{3} & \tilde{k}_{3}+\tilde{k}_{4} & -\tilde{k}_{4} \\
0 & -\tilde{k}_{4} & \tilde{k}_{4}
\end{array}\right] \cdot\left(\begin{array}{c}
\tilde{x}_{2} \\
\tilde{x}_{3} \\
\tilde{x}_{4}
\end{array}\right)=\left(\begin{array}{c}
\tilde{0} \\
\tilde{0} \\
\tilde{0}
\end{array}\right)} \\
& {[\tilde{m}](\tilde{\ddot{x}})+[\tilde{c}](\tilde{\dot{x}})+[\tilde{k}](\tilde{x})=(\tilde{F})}
\end{aligned}
$$

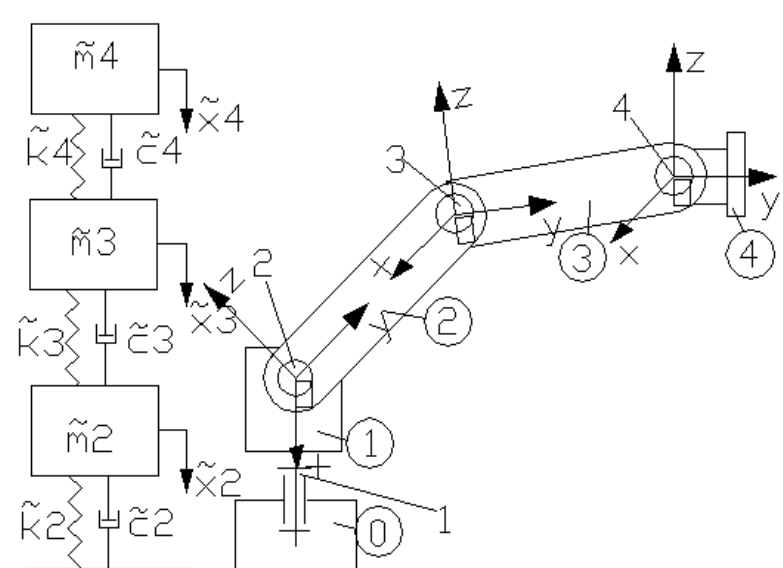

Fig. 10. Block schema of the robots with springs, dampers and mass.

where: $\tilde{m}_{i}$ is the inertial tensor of $i$ body; $\tilde{\ddot{x}}_{i}$ - angular acceleration matrix partition; $\tilde{c}_{i}$ - damper partition; $\tilde{k}_{i}$ stiffness partition; $\tilde{x}_{i}$ - angular displacement partition; $\tilde{\dot{x}}_{i-}$ angular velocity partition; $\tilde{F}$ - momentum column partition; $k_{x i^{-}}$axial stiffness of $i$ body; $c_{x i^{-}}$axial damper in $i$ joint; $k^{-1}$ the compliance matrix. For the determination of the vibration structure's modes was necessary to write the dynamic matrix $[d]$ and the ortho dynamic matrix $[b]$ [20]. If the compliance matrix will be calculated without frequency variation this will be the static local compliance matrix. If the compliance matrix will be calculated with frequency variation this will be the local dynamic compliance matrix. The local dynamic compliance matrix is calculated for each component of the robot's structure. Every mechanical robot structure consists of multiple mechanical components witch are coupled together and can be represented in a static and dynamic mechanical model as multiple mass, spring and damping elements. While the mass and the spring stiffness determine the natural frequency $v_{\mathrm{n}}$ of the system, the damping element, represented by the GDDR $\xi$, governs the resonance amplitude of the vibration and with it, the dynamic system stiffness and the GDC. Modal testing theory has been successfully used for calculating the frequency spectrum of robots structure [20]. The characteristics of the displacement and force (to determine the GDC) vs. frequency and the phase- frequency and the amplitudefrequency characteristics of the mechanical robot structure was determined. Frequency characteristics analysis is important to understand the dynamic performance of the bodies- joints robot system. If the dynamic impact with one periodical force on the base of the robot structure is $F(t)$, the displacement response of the TCP is $x(t)$, then the GDC of the TCP is defined versus frequency as: 


$$
\frac{1}{k(j \omega)}=\frac{\int_{0}^{T} x(t) e^{-j \omega t} d t}{\int_{0}^{T} F(t) e^{-j \omega t} d t}=\frac{F F T(x)}{F F T(F)}=\frac{E_{x}(j \omega)}{E_{F}(j \omega)}
$$

where $E_{F}(j \omega)$ and $E_{x}(j \omega)$ are complex spectrum of energy of the input force on the base robot modulus and respectively output displacement of the TCP. The complex power spectrum is possible to obtain by dividing the energy spectrum with the integration time $t$. The integrated relations are the Fourier transform expressions and can be calculated by FFT algorithm [21-28].

Magnitude of the GDC was calculated by:

$$
\frac{1}{k(\omega)}=\sqrt{\left(\operatorname{Re}\left\{\frac{1}{k(j \omega)}\right\}\right)^{2}+\left(\operatorname{Im}\left\{\frac{1}{k(j \omega)}\right\}\right)^{2}}
$$

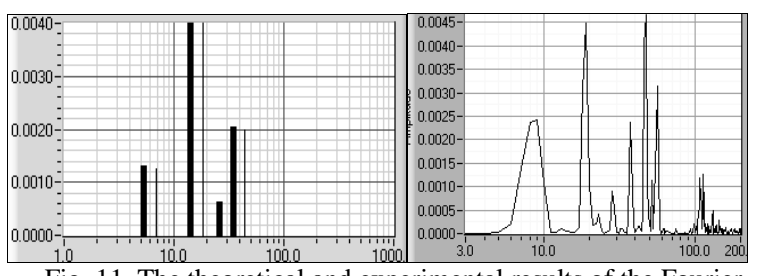

Fig. 11. The theoretical and experimental results of the Fourier spectrum.
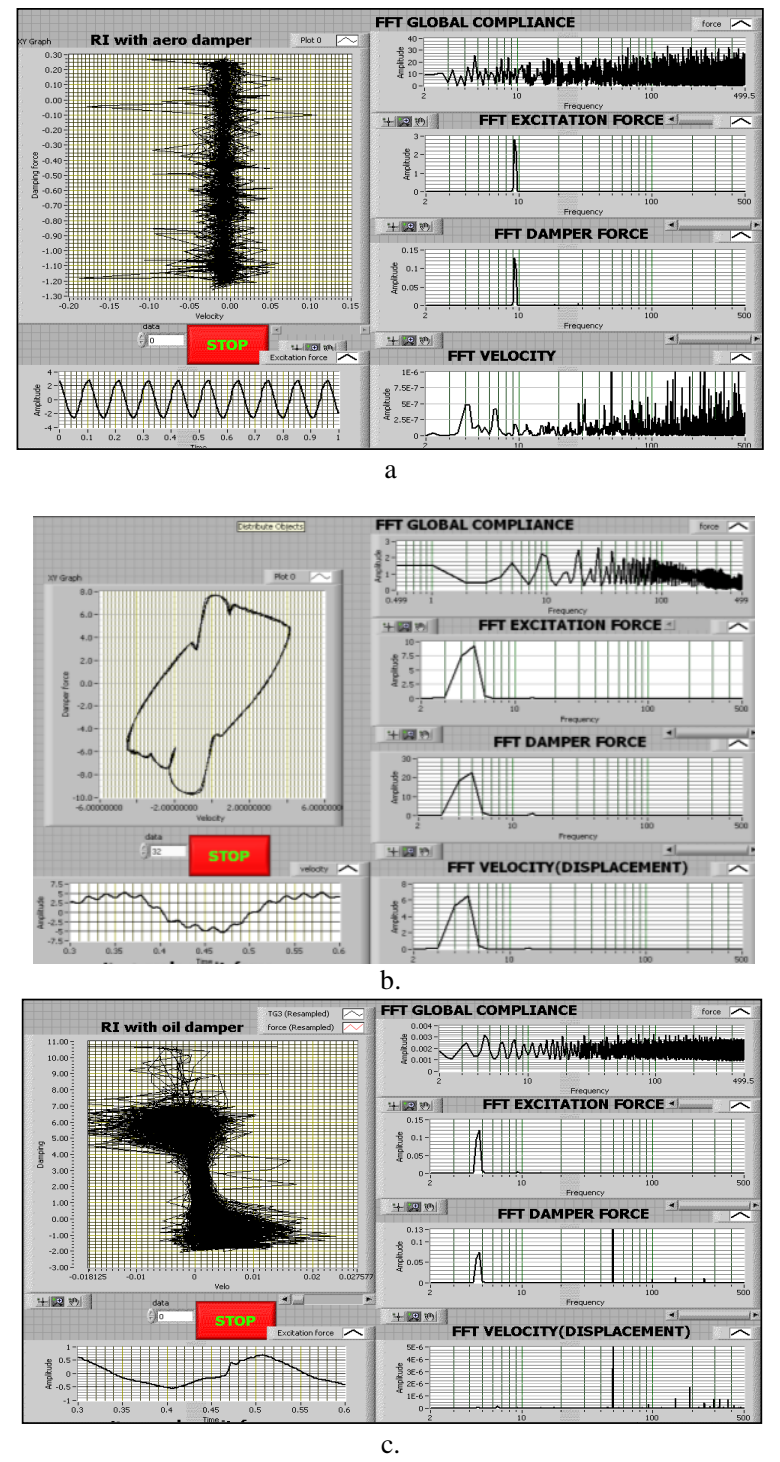

Fig. 12. Damper force vs. displacement a- without damper; b- with aerodamper; c- with magneto rheological damper.
After analysing the results we can do the following remarks: the first resonance frequency of the didactical arm type robot structure was $14[\mathrm{~Hz}]$; with the complex characteristics damper force vs.velocity was possible to determine the damper energy for one cycle for each of the studied cases; we can see that in the case of the research with MRD, the force vs. velocity characteristic have two slopes determined by the two state of the magnetorheological fluid: liquid and gel and it is possible to see the velocity when was changed the state of the flow.

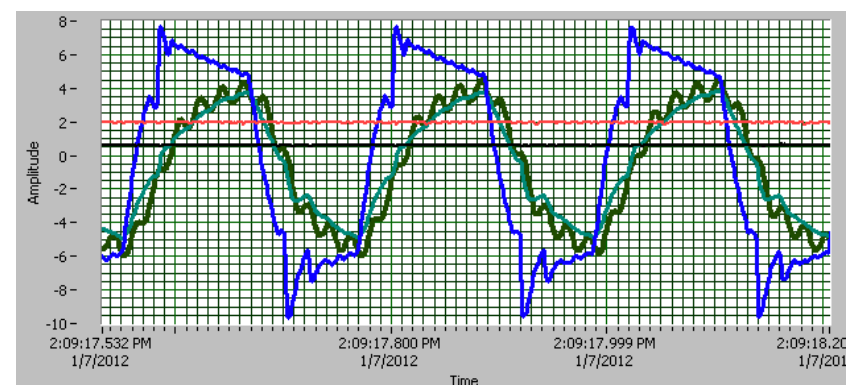

Fig. 13. The real characteristics of velocity --- of the end- effecter; of the excitation force ---; of the damper force

\section{OPTIMIZATION OF THE INVERSE KINEMATICS RESULTS}

The optimization of the inverse kinematics is the more important problem of the controlling the space trajectory of the robots. More over for the multi robots application without one precise method isn't possible to control all movements. For that, to obtain the extreme precision was used one complex coupled method Iterative Pseudo Inverse Jacobian Matrix Method with Sigmoid Bipolar Hyperbolic Tangent Neural Network with Time Delay and Recurrent Links (IPIJMM-SBHTNN-TDRL) [29]-[40].

Neural network are composed of simple elements operating in parallel, like a biological nervous systems. As in nature, the connections between elements largely determine the network function. You can train a neural network to perform a particular function by adjusting the value of the connections (weights) between elements, the hidden targets and the biases. Neural network have been trained to perform complex functions in various fields including pattern recognition, identification, classification, speech, vision and control systems. We consider neural network as an alternative computational scheme rather than anything else. The artificial neural networks which we described in this paper are all variation on Parallel Distributed Processing (PDP) idea. An artificial network consists of a pool of simple processing units which communicate by sending signals to each other a large number of weighted connections. Typically, neural network are adjusted, or trained, so that a particular input leads to specific target output. There, the network is adjusted, based on comparison of the output and the target, until the network's output touch the target. Typically, many such input/target pairs are needed to train a network. These we were made with the goal to obtain the minimal variation of the velocity and position errors between the real and the simulate model, to be able to compensate them by electrical feedback compensation:

$$
\varepsilon_{\text {cin }}=\left|\dot{q}_{i}(t)-\dot{q}_{\text {trap }}(t)\right| \leq \varepsilon_{\text {adm }} ;
$$




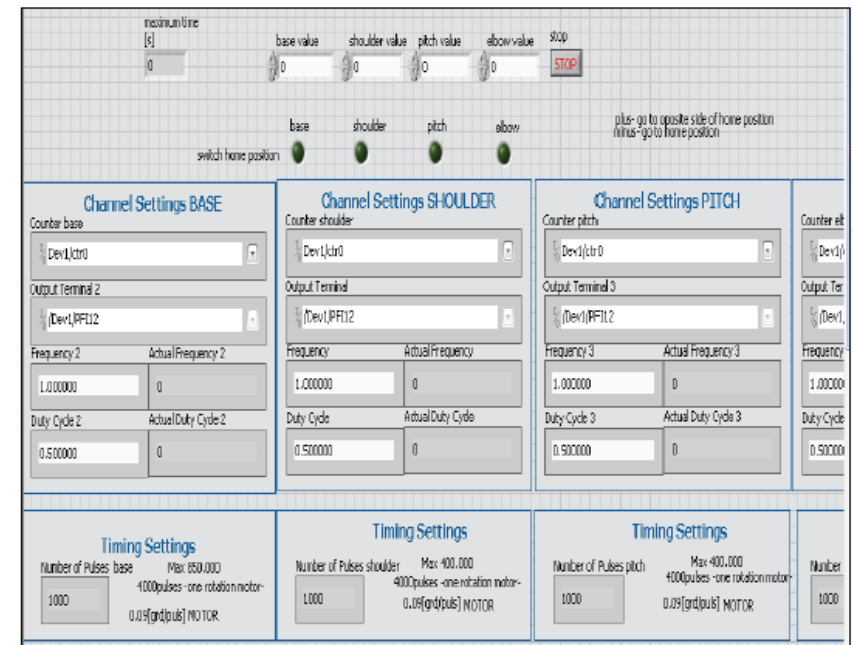

Fig. 14. The front panel of the LabVIEW VI-s for controlling the robot with DC motors and encoders.

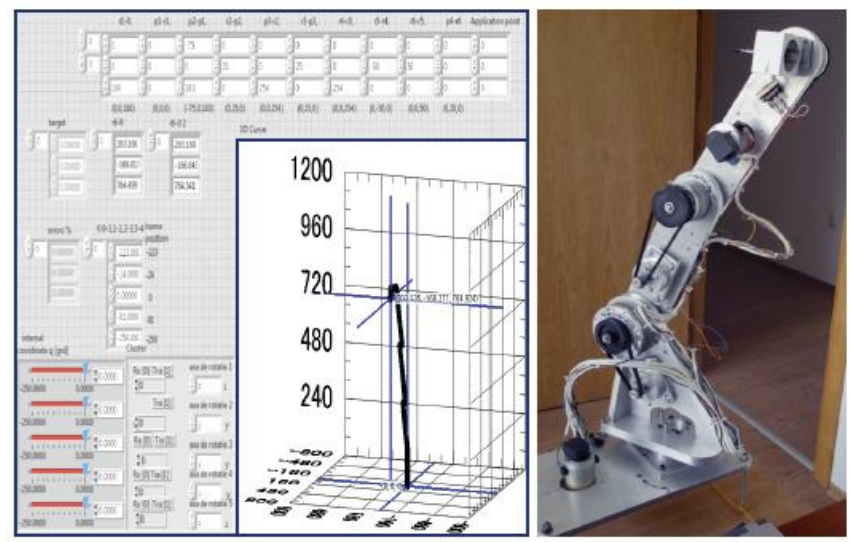

Fig. 15. The front panel with input data and the robot with DC motorsencoders and Gekodrive GK330 and acquisition board National Instruments PCi 6221.

Using the VI enabled us to easily verify and compare the navigated spatial trajectory with the programmed trajectory, based on which the errors around all space curves could be determined. As a result, such a tool can be used to adjust and finalize the internal coordinates in offline, and paves the way for programming a wide variety of robots in numerous applications that require extreme precisions and accuracy.

\section{Optimization of the ApPlied Robot Base Point}

In this kind of application will be necessary to find the better position of the application base robot's point in the $3 \mathrm{D}$ space to obtain the minimum time of robot work. The algorithm contents the inverse kinematic solving of the used robot, the forward kinematics and neural network to obtain the internal coordinate that assures the touching space target with one precision more than $0.001 \mathrm{~mm}$. The application points are finding in one cube that follows the constraints conditions. The proposed algorithm Pseudo- Inverse Jacobian- MatrixMethod with Sigmoid- Bipolar- Hyperbolic- TangentNeural- Network with Time- Delay and Recurrent- Links (PIJMM- SBHTNN- TDRL) will be applied for all application points of robot [41-45], points that will be obtained by interpolation between the constraints limits of the base point of the robot. After that, will be resulted the internal coordinates that assured also the extreme precision and the better position of the robot's base. The objective function of optimization problem is calculate for all possible application points $p_{i}$, represents the minimum time of motion between points $P_{1}$ and $P_{i}$ of the proposed application, when the application is multi robots and the movements of all joints are successively:

$$
F\left(P_{i}\right)=\min \left(\sum_{i_{=1}}^{n} \max \left(\frac{q_{i}}{q_{i}} \forall p_{i i} \in_{\Delta_{1}}\right)\right)
$$

and the constraints:

$q_{\text {i min }}<q_{i}<q_{\text {i max }} ; P_{\text {imin }_{\text {min }}}<P_{i}<P_{\text {imax }_{\text {max }}} ; q_{\text {i min }}^{\prime}<q_{i}^{\prime}<q_{\text {i max }}^{\prime}$; or the movements are simultaneously:

$$
F\left(P_{i}\right)=\min \left(\sum_{i=1}^{n} \sum_{i_{i=1}}^{q_{i}} \frac{q_{i}}{q_{i}} \forall p_{i i} \in_{\Delta_{1}}\right)
$$

where: $m$ is the number of DOF; $n$ is the number of robots in application, $i$ - the degree of freedom of each robot, $q_{i}$ - the movement in each joint; $q_{i}^{\prime}$ is the velocity in each robot's joints; $p_{i}$ is the possible application points to belong of the acceptable field $A ; P_{i}$ is the end effecter point that must be inside of the working space.

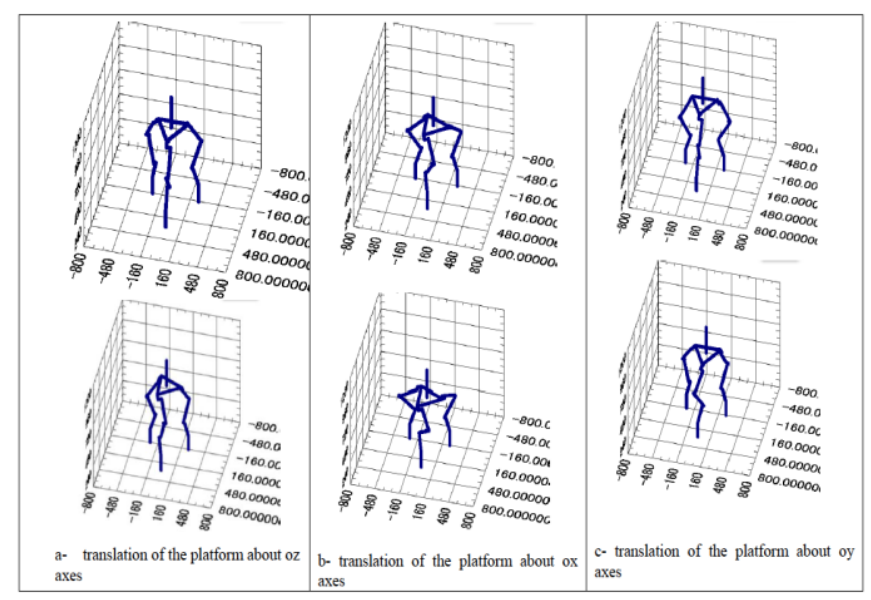

Fig. 16. Parallel robot structure with triangle platform in a ox, oy and oz translations.

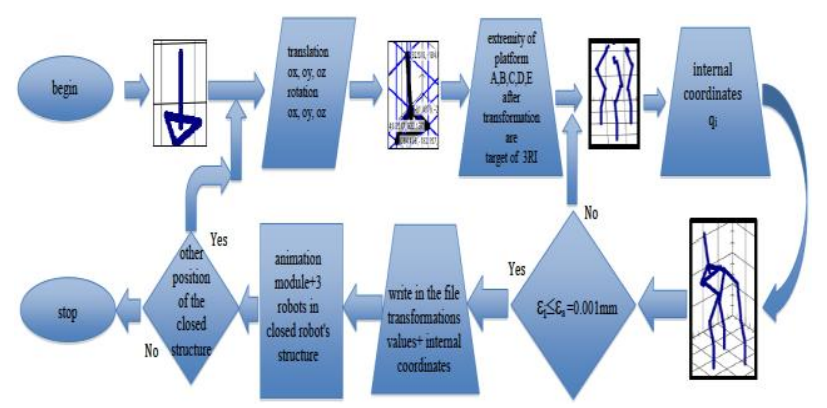

Fig. 17. Block schema of the applied algorithm for the assisted controlling of the 3D space trajectory of the parallel robot's structure with triangle platform.

\section{PARAllel Robot's Structure With Three ARm TYPE ROBOTS}

In the paper was shown one parallel robot's structure with triangle platform. Some examples and the block schema of the algorithm are shown in Figs.16-17.

In Fig. 17 is shown one complex block schema of the algorithm for the parallel robot's structure. The algorithm contents the following LabVIEW ${ }^{\mathrm{TM}} V I$-s: one $V I$-s is for the 
design of the mobile platform of which the extremities will be targets for the arms of the three robots within the parallel structure with different application points; other VI-s is for establishing the position in the space of the platform after apply three rotations and three translations; other VI-s is for calculate the internal coordinates for all three robot's parallel structure to touch these targets with the precision better than $0.001 \mathrm{~mm}$. The position in the space of the platform, the defined targets, the design of the platform in one new space position, the internal coordinates for all three robots represent the complete design of the parallel structure; the other $V I$-s can animate the parallel robot's structure for different space position. $V I$-s gives the possibility to define successive points of one desired $\Gamma$ space curve. With other $V I$-s will be calculate for all targets points from the $\Gamma$ space curve all required internal coordinates for all robot's joints [46]-[50].

\section{CONCLUSION}

After analyzing the applied method, the simulation and animation $V I$-s, the obtained results, we can make the following remarks: (i) optimal choose of the precisionstability working point of one linear hydraulic cylinder by using the Extenics theory open the way for the optimising the elements and the servosystems of the robots; (ii) modelling and optimization of the DC electrical drive of the robots by using the proper mathematical model and the assisted research with labVIEW ${ }^{\mathrm{TM}}$ instrumentation give to the researchers in this field many information about the dynamic behaviour of the complex systems and how the constructive and functional parameters of the systems change the behaviour and how can be find the better solution; (iii) optimising the dynamic behaviour of the robots by using the intelligent dampers by introduce the new terms like GDC, VGGDC or other could be used in many research where must obtain the optimal dynamic behaviour; (iv) optimise the inverse kinematics results by using one complex proper method assures one extreme precision of controlling and open the way to use this algorithm for the parallel robot's structure; (v) optimise the multi robots application by using the algorithm to choose the optimal application points of the robots' bases to decrease the consumption of the energy; (vi) the extreme precision obtained for the three different targets open the way to construct the parallel robot structure using the same three arm type robots and also the complex controlling algorithm; (vii) the complex matrix method to solve the Forward kinematics (FK) and also the Inverse Kinematics (IK) are checked and could be applied in the future; (viii) the complex program of the multi robots and parallel robot animation contains many LabVIEW ${ }^{\mathrm{TM}} V I$-s that assures very easily to control the end-effecters with precision better than $0.001 \mathrm{~mm}$; (ix) the simulation and experimental modeling of a scenario of simulating the movement of the robots' TCP on a known target curve $\Gamma$ via LabVIEW $^{\mathrm{TM}}$, enabled us to analyze and optimize the control of motors' movement in offline; (x) this method and the proposed program can be used off-line in many parallel robot application; (xi) the animation program confirm the validity of the applied algorithm and also the assisted applied method; (xii) this work open the way to the construction and optimizing the space movements of the parallel robot's structure in the design with platform with three legs robots; (xiii) all created LabVIEW $V I$-s are generally and they can be used in many other application when it is necessary to obtain the extreme precision and accuracy; (xiv) the proposed method, the algorithm and the LabVIEW ${ }^{\mathrm{TM}} V I$-s can be applied in many other application of the complex open and closed robot's structures and also in collaborative applications when will be appeared workers and the security systems for workers. As for future work, based on the presented results, we plan to develop more complex LabVIEW $^{\mathrm{TM}} V I$-s to apply this method to different parallel robot applications in collaborative manner and for different conventional and unconventional space curves.

\section{ACKNOWLEDGMENT}

The authors tanks to University Politehnica of BucharestMachine and Manufacturing Systems Department, RomSys Company, TechnoAccord Company and Technical University from Kosice, Slovakia for technical support of this research and also sustained by RUSOS international project.

\section{REFERENCES}

[1] W. Cai, "The extension set and non-compatible problems," AMM in China, International Academic Publisher, 2, pp. 1-21, 1990.

[2] W. Cai, "Matter-element models and their applications," Science and Technology Document, Publishing House, China, 1994.

[3] C. Y. Yang and W. Cai, Extenics: Theory, Method and Application, Science Press, China, 2002.

[4] A. Olaru, Virtual LabVIEW Instrumentation in the Technical Research of the Robots Elements and the Systems, Bren Publishing House, 2002, pp. 68-75.

[5] A. Olaru, "Dynamic of the industrial robots", vol. 2, Bren Publishing House, 2001, pp. 167-175.

[6] A. Olaru and Mihai, N., "Dynamic of the industrial robots," vol. 1, Bren Publishing House, 1999, pp.106-120.

[7] A. Oprean and A. Olaru, "Theoretical and experimental analyze of position and velocity at articulated arm industrial robot," in Proc. Int. Conf. On Solid Mechanics, Romanian Academy, 2001, pp. 230-238.

[8] A. Olaru, "Theoretical and experimental research of cinematic and dynamic behavior of industrial robots," in Proc. $12^{\text {th }}$ International DAAAM Symposium, 2001, pp. 333-334.

[9] A. Olaru, "Assisted analyze of the extenics dependent functions in 1D,2D,3D and nD Dimensions with LabVIEW Instrumentation," ICNCT2013, 2013

[10] J. Angeles, F. Ranjbaran and R. V. Patel, "On the design of the kinematic structure of seven axes redundant manipulators for maximum conditioning," in Proc. IEEE Int. Conf. Robotics and Automation, pp. 494-499, Nice, France, May 1992.

[11] J. Angeles, Fundamentals of Robotic Mechanical Systems: Theory, Methods, and Algorithms, 3rd Edition, Springer \& Verlag, New York, 2006.

[12] G. Antonelli, G. Indiveri, and S. Chiaverini, "Prioritized closed loop inverse kinematic algorithms for redundant robotic systems with velocity saturations," Int. Conf. on Intelligent Robots and Systems, pp. 5892-5897, 2009.

[13] C. Carignan, "Trajectory optimization for kinematically redundant arms," Journal of Robotic Systems, vol. 6, no. 5, pp. 221-248, 1991.

[14] M. Hajduk, J. Semjon, and M. Vagaš, "Design of the welding fixture for the robotic station for spot weldind based on the modular concept," Acta Mechanica Slovaca, vol. 13, pp. 30-35.

[15] M. Hajduk, M. Sukop, V. Baláž, J. Semjon, and M. Vagaš, "Improving the performance of manufacturing systems based reconfiguring and computer integration," Proceed.of Robtep, Košice, 2006.

[16] D. J. Ewins, Theory and Practice, In Modal Testing; John Wiley \& Sons, Inc.:New York, 1984.

[17] E. O. Brigham, "In the fast fourier transform and its applications," Englewood Cliffs, New Jersey, 1988.

[18] T. Butz and O. Stryk, Modelling and Simulation of Rheological Devices, In Sonderforshungsbereich 438, Tehnische Universitat Munchen, Universitat Augsburg, 1999.

[19] S. Olaru, A. Oprean, A. Olaru, "Assisted research of the new Bouc-Wen rheological damper," in Proc. OPTIROB 2008, pp. 143-152, 2008. 
[20] A. Olaru and S. Olaru, "Research of the industrial robots viscose global dynamic damper coefficient with LabVIEW instrumentation," in Proc. CAX'2006, pp. 73- 81, 2006.

[21] M. Tesch, K. Lipkin, I. Brown, R. Hatton, A. Peck, J. Rembisz, and H. Choset, "Parameterized and scripted gaits for modular snake robots," Advanced Robotics, vol. 23, no. 9, pp. 1131-1158, Jun. 2009.

[22] D. R. Jones, "A taxonomy of global optimization methods based on response surfaces," Journal of Global Optimization, vol. 21, no. 4, pp. 345-383, 2001.

[23] J. L. Cohon, "Multiobjective programming and planning," Courier Dover Publications, 2004.

[24] V. Coverstone-Carroll, "Optimal multi-objective low-thrust spacecraft trajectories," Computer Methods in Applied Mechanics and Engineering, vol. 186, no. 2-4, pp. 387-402, Jun. 2000.

[25] J. Knowles, "ParEGO: a hybrid algorithm with on-line landscape approximation for expensive multi objective optimization problems," IEEE Transactions on Evolutionary Computation, vol. 10, no. 1, pp. 50-66, Feb. 2006.

[26] L. Dixon and G. Szego, "The global optimization problem: An introduction," Towards Global Optimization, vol. 2, pp. 1 - 15, 1978.

[27] A. Zilinskas, "Are view of statistical models for global optimization," Journal of Global Optimization, vol. 2, no. 2, pp. 145-153, Jun. 1992.

[28] Y. P. Papalambros and J. D. Wilde, "Principles of optimal design," Modeling and Computation, Cambridge University Press, 1988.

[29] T. Yoshikawa, "Manipulability of robotic mechanisms," International Journal of Robotic Research, vol. 4, no. 2, pp. 3-9. 1985.

[30] H. Asada, "A geometrical representation of manipulator dynamics and its application to arm design, transactions of ASME," Journal of Dynamic Systems., Meas. and Control, vol. 105, pp. 131-135. 1983.

[31] T. Graettinger and B. H. Krogh, The acceleration radius: A global performance measure for robotics manipulators, "Journal of Robotics and Automation, vol. 4, no. 1, Feb 1988.

[32] A. Bowling, "Analysis of robotic manipulator dynamic performance: Acceleration and force capabilities," PhD-thesis, Stanford University, 1998.

[33] M. Ou and J. Angeles, "Optimum design of manipulators under dynamic isotropy conditions," in Proc. IEEE International Conference on Robotics and Automation, vol. 1, pp. 470-475, 1993.

[34] W. A. Kahn and J. Angeles, "The kinetostatic optimization of robotic manipulators: The inverse and the direct problems," Transactions of the ASME Journal of Mechanical Design, vol. 128, no. 1, pp. 168-178, 2006.

[35] J. K. Salisbury and J. J. Craig, "Articulated hands: Force control and kinematic issues," International Journal of Robotics Research, vol. 1, no. 1, pp. 4-17, 1982.

[36] S. Kirkpatrick, C. D. Gelatt, and M. P. Vecchi, "Optimization by simulated annealing," Science, Vol. 220, pp. 671-680, 1983

[37] L. Ciupitu, Complex Analytic Curves for Industrial Robot Trajectories, in Proc. the 3-rd Asian Conference on Robotics and Its Application, Tokyo, Japan, pp. 211-218.

[38] L. Ciupitu and I. Simionescu, "Optimal location of robot base with respect to the application positions," in Proc. the 2-nd International Conference on "Optimization of the Robots and Manipulators" OPTIROB 2007, Predeal, Romania, 27-29 May 2006,

[39] L. Ciupitu, S. Brotac, and S. Chivescu, "Optimum Position of an Industrial robot used in forge applications," in Proc. 4-th International Conference on "Optimization of the Robots and Manipulators" OPTIROB 2009," 2009, pp. 43-47.

[40] J. Denavit and R. S. Hartenberg, "A kinematic notation for lower-pair mechanisms based on matrices," Trans. of ASME, Journal of Applied Mechanics, pp. 215-221.

[41] J. T. Feddema, "Kinematically optimal placement for minimum time coordinated motion, robotics and automation," vol. 4, 1996, pp. 3395-3400.

[42] F. Kovacs and G. Cojocaru, Manipulatoare, Roboţi Şi Aplicaţiile Lor Industriale, Editura Facla, Timişoara, 1982.

[43] I. Simionescu, V. Moise, and L. Ciupitu, "Sinteza funcţiilor de transmitere ale mecanismelor," Journal of Romanian Academy "Studii şi cercetări de mecanică aplicată," 1996, pp. 409-426.

[44] I. Simionescu and L. Ciupitu, "On the optimisation of industrial robot motions," vol. 2, 1997, pp. 333-338.

[45] I. Simionescu and L. Ciupitu, "Optimum programming of industrial robot trajectories," in Proc. 3-rd Asian Conference on Robotics and Its Application, Tokyo, Japan, 29- 30 October 1997, pp. 219-224.

[46] L. Tian and C. Collins, "Optimal placement of a two-link planar manipulator using a genetic algorithm," Robotica Journal, Cambridge University Press, 2005, vol. 23, pp. 169-176.

[47] A. Olaru, S. Olaru, and N. Mihai, "Proper assisted research method solving of the robots inverse kinematics problem," Applied Mechanics and Materials, 2014, pp. 135-147.

[48] A. Olaru, S. Olaru, and L. Ciupitu, "Assisted research of the neural network by back propagation algorithm," in Proc. OPTIROB 2010 International Conference, Calimanesti, Romania, 2010, pp. 194-200.

[49] A. Olaru, S. Olaru, and N. Mihai, "Proper assisted research method Solving of the robots inverse kinematics problem," Applied Mechanics and Materials, vol.555, 2014, pp. 135-147.

[50] A. Olaru, S. Olaru, and L. Ciupitu, "Assisted research of the neural network by back propagation algorithm," in Proc. OPTIROB 2010 International Conference, Calimanesti, Romania, May 28-th-30-th, 2010, TheResearch Publishing Services Singapore Book, 2010.

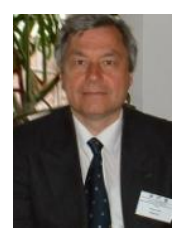

Adrian Olaru finish the University Politehnica of Bucharest, the Faculty of Machine-Tools, Machine and Manufacturing Systems Department. Now, from $1998 \mathrm{He}$ is a university full professor, and $\mathrm{He}$ teach the following coursesare industrial robots dynamics behavior, LabVIEW application in modeling and simulation of the dynamic behavior of robots and Personal and social robots. He is a doctor from 1989. In the last ten years He has been leading the following research projects: computer aided research and design for the hydraulic amplifiers of pneumatic and hydraulic screwdrivers; computer aided research over the dynamic behavior of the forging manipulator orientation modulus; computer aided research over dynamic behavior of the charging manipulators tipping modulus; computer aided research over dynamic behavior of the charging manipulators translation modulus; experimental validation for mathematical models of hydraulic elements and servo system and many others.

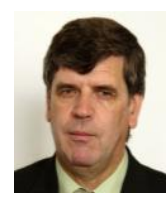

Mikulas Hajduk is a head of the Department of Automatisation and Robotics from Technical University of Kosice, Slovakia. He written more than 15 technical books and over than 200 research papers concerning the robots, mobile robots, collaborative robots and also in the field of intelligent manufacturing systems

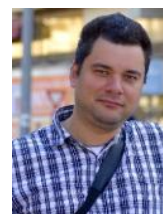

Serban Olaru finished the University Politehnica of Bucharest, Faculty of Machines and Manufacturing Systems, Romania. From 2008 he become the Ph.D.Eng.in the field of mechatronics. Now, he works in RomSYS private company, from Bucharest, Romania, in the department of mechatronics. He write mote than 50 research papers in the fields of intelligent damper systems, mechatronic systems, simulation and modeling with LabVIEW instrumentation.

Niculae Mihai finished the University Politehnica of Bucharest, Faculty of Machines and Manufacturing Systems, Romania.

From 2006 he become Ph.D.Eng. in the field of robotics. Now, he is the manager of the private company in mechatronics systems, Technoaccord, Quebec, Canada.

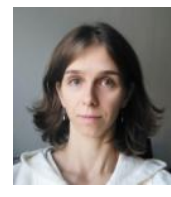

Natalia Smidova was graduated from Faculty of Mathematics and Physics, Charles University in Prague in 2005, works at Department of Physics, Faculty of Electrica Engineering and Informatics, Technical University of Kosice. Oriented on investigation of material properties by spectroscopic (nuclear magnetic resonance (NMR) and Raman) methods; She is interested in polymers and polymer nanocomposites made from renewable resources. 